\title{
Exon-intron structure and sequence variation of the calreticulin gene among Rhipicephalus sanguineus group ticks
}

Daniele Porretta ${ }^{1}$, Maria Stefania Latrofa ${ }^{2}$, Filipe Dantas-Torres ${ }^{2,3}$, Valentina Mastrantonio ${ }^{1}$, Roberta latta ${ }^{2}$, Domenico Otranto ${ }^{2^{*}}$ and Sandra Urbanelli ${ }^{1}$

\begin{abstract}
Background: Calreticulin proteins (CRTs) are important components of tick saliva, which is involved in the blood meal success, pathogen transmission and host allergic responses. The characterization of the genes encoding for salivary proteins, such as CRTs, is pivotal to understand the mechanisms of tick-host interaction during blood meal and to develop tick control strategies based on their inhibition. In hard ticks, crt genes were shown to have only one intron with conserved position among species. In this study we investigated the exon-intron structure and variation of the crt gene in Rhipicephalus spp. ticks in order to assess the crt exon-intron structure and the potential utility of crt gene as a molecular marker.
\end{abstract}

Methods: We sequenced the exon-intron region of crt gene in ticks belonging to so-called tropical and temperate lineages of Rhipicephalus sanguineus (sensu lato), Rhipicephalus sp. I, Rhipicephalus sp. III, Rhipicephalus sp. IV, R. guilhoni, R. muhsamae and R. turanicus. Genetic divergence and phylogenetic relationships between the sequences obtained were estimated.

Results: All individuals belonging to the tropical lineage of R. sanguineus (s.l.), R. guilhoni, R. muhsamae, R. turanicus, Rhipicephalus sp. III and Rhipicephalus sp. IV analysed showed crt intron-present alleles. However, both crt intron-present and intron-absent alleles were found in Rhipicephalus sp. I and the temperate lineage of $R$. sanguineus (s.I.), showing the occurrence of an intraspecific intron presence-absence polymorphism. Phylogenetic relationships among the $\mathrm{crt}$ intron-present sequences showed distinct lineages for all taxa, with the tropical and temperate lineages of $R$. sanguineus (s.l.) being more closely related to each other.

Conclusions: We expanded previous studies about the characterization of crt gene in hard ticks. Our results highlighted a previously overlooked variation in the crt structure among Rhipicephalus spp., and among hard ticks in general. Notably, the intron presence/absence polymorphism observed herein can be a candidate study-system to investigate the early stages of intron gain/loss before fixation at species level and some debated questions about intron evolution. Finally, the sequence variation observed supports the suitability of the crt gene for molecular recognition of Rhipicephalus spp. and for phylogenetic studies in association with other markers.

Keywords: Hard tick, Rhipicephalus sanguineus group, Intron evolution, Intron presence-absence polymorphism, Tick control, Genetic markers

\footnotetext{
*Correspondence: domenico.otranto@uniba.it

${ }^{2}$ Department of Veterinary Medicine, University of Bari, 70010 Valenzano, Bari, Italy

Full list of author information is available at the end of the article
} 


\section{Background}

Calreticulins (CRTs) are calcium-binding proteins that have been found in a broad range of eukaryotic organisms, both invertebrates and vertebrates [1-3]. They can be implicated in many cellular functions, including cell proliferation, calcium storage, protein folding, modulation of gene expression, cell apoptosis and cell differentiation [4-6].

In ticks, CRTs are important components of tick saliva, which plays a pivotal role in tick feeding and pathogen transmission to hosts by acting as anti-haemostatic, anti-inflammatory and immunomodulatory molecules [7-15]. In this context, CRTs have been suggested to play a modulating role in host haemostasis $[9,16,17]$ and have been shown to be highly immunogenic to tick mammalian hosts [18-21]. These findings have fuelled the interest for CRTs, as they could be used as targets for diagnostic tools (e.g. for detecting exposure to tick bites) and vaccines [22]. Several studies were therefore focused on the genetic characterization of CRTs and to date $c r t$ genes have been sequenced in several hard tick species [23-26]. Comparative analysis of the exon-intron structure of $\mathrm{crt}$ genes in 28 hard tick species belonging to different genera, including Amblyomma, Dermacentor, Ixodes and Rhipicephalus showed that (i) two exons and only one intron are present in tick crt genes, contrary to what was observed in other invertebrate and vertebrate species (i.e. two introns in nematodes, three in fruit flies, seven in mouse and eight in humans); (ii) the intron position is conserved in hard ticks, although the intron size and nucleotide sequences vary among species [24, 25]. Noteworthy, the crt gene has been found to be expressed in salivary glands and in several other tissues (i.e. cuticle, gut, fat body, ovaries) and at different tick developmental stages [24, 26], where CRTs are likely involved in multiple cellular functions as described above [4]. Crt genes could be therefore good target sites for control strategies based on gene expression silencing approaches such as RNA interference (RNAi), as their silencing could not only affect the success of tick blood feeding and pathogen transmission but also tick physiology and fitness [27, 28].

In addition, crt are single-copy genes [4] and the occurrence of a conserved intron-exon structure makes them a potential good exon-primed intron-crossing (EPIC) marker to be used in phylogenetic studies among closely related taxa [29-32]. EPIC, having both the exon and intron fragments, could help in examining genetic variation at the intraspecific and interspecific level simultaneously, which could be particularly helpful when studying a species complex [29, 30,32].

Among ticks, the Rhipicephalus sanguineus group is particularly important from medical and veterinary viewpoints, as its members are vectors of several tick-borne pathogens causing diseases in dogs (e.g. Ehrlichia canis, Babesia vogeli and Hepatozoon canis) and humans (e.g. Rickettsia conorii and Rickettsia rickettsii) [33-35]. In the last two decades, ecological, morphological and genetic studies have concordantly supported the occurrence of distinct cryptic species within this group, whose geographic distribution, taxonomic status and phylogenetic relationships are still debated [36-39].

To date, $c r t$ gene sequence has been obtained only from a single individual of $R$. sanguineus (sensu lato) from Colombia [24, 25]. Indeed, sequence diversity and structure of the $c r t$ gene have been poorly investigated within and among members of the $R$. sanguineus group. In the context, we aimed to contribute to address this gap by analysing the crt gene in different Rhipicephalus spp., including $R$. sanguineus (s.l.), $R$. turanicus, $R$. guilhoni, $R$. muhsamae and additional Operational Taxonomic Units (OTUs) that have been recently identified on the basis of morphological and molecular analysis [40]. Therefore, the crt exon-intron region from each individual was sequenced and analysed among species and the OTUs listed above. The ability of the crt gene sequence to correctly identify the individuals analysed was also tested to assess its potential utility as a molecular marker for Rhipicephalus spp.

\section{Methods}

\section{Ticks}

Ticks belonging to the $R$. sanguineus group used in this study are a subset of the ticks morphologically and genetically identified in the study of Dantas-Torres et al. [40]. They include individuals of $R$. sanguineus (s.l.) (= "tropical species"), Rhipicephalus sp. I, Rhipicephalus sp. II (= "temperate species"), Rhipicephalus sp. III, Rhipicephalus sp. IV, R. turanicus and R. guilhoni. For clarity's sake, ticks referred to as " $R$. sanguineus (s.l.)" and "Rhipicephalus sp. II" in Dantas-Torres et al. [40] will be referred here as tropical and temperate lineages, respectively, as these designations have been consensually used in the literature. Taxa with at least three individuals each and from different geographic areas were selected (Table 1). One R. muhsamae individual, which does not belong to the $R$. sanguineus group, was also included. The genomic DNA of each tick, previously extracted [40], was used for amplification and sequencing of the $c r t$ gene.

\section{PCR amplification and sequencing}

We initially amplified and sequenced a crt fragment that includes the intron region using the degenerate primers pair CRT32DF 5'-ATG CGG STY STS TGC WTK TTG C-3'; CRT1268DRC 5'-CTC AMA RYT CYT CGT GST YGT G-3' [25]. Then a new primer pair (Rsang-crt-F 5'-CAT TTT GCT TCC CCT GGT-3'; Rsang-crt-R 5'-TGT TCT GTT CGT GCT TGA-3') was 
Table 1 Rhipicephalus spp. ticks analysed. Individuals with the same Genbank accession number share the same haplotype

\begin{tabular}{|c|c|c|c|c|c|c|c|}
\hline Species & Code & Geographical origin & Intron & 5' splice donor & $\begin{array}{l}\text { Intron } \\
\text { size (bp) }\end{array}$ & 3' splice donor & $\begin{array}{l}\text { GenBank } \\
\text { accession } \\
\text { number }\end{array}$ \\
\hline R. sanguineus ${ }^{a}$ & - & Colombia & yes & GGAG/gtgagta & 341 & gtgcag/ATGC & AY395275 \\
\hline \multirow[t]{7}{*}{ Tropical lineage } & tick224 & Vietnam (Ho Chi Minh City) & yes & GGAG/gtgagta & 338 & gtgcag/ATGC & KX951737 \\
\hline & tick228 & Thailand (Bangkok) & yes & GGAG/gtgagta & 338 & gtgcag/ATGC & KX951737 \\
\hline & tick230 & Thailand (Bangkok) & yes & GGAG/gtgagta & 338 & gtgcag/ATGC & KX951738 \\
\hline & tick249 & Honduras (San Pedro) & yes & GGAG/gtgagta & 338 & gtgcag/ATGC & KX951746 \\
\hline & tick250 & Honduras (San Pedro) & yes & GGAG/gtgagta & 338 & gtgcag/ATGC & KX951737 \\
\hline & tick259 & Costa Rica (San Jose) & yes & GGAG/gtgagta & 340 & gtgcag/ATGC & KX951746 \\
\hline & tick260 & Costa Rica (San Jose) & yes & GGAG/gtgagta & 340 & gtgcag/ATGC & KX951746 \\
\hline \multirow[t]{11}{*}{ Rhipicephalus sp. I } & tick129 & Italy (Putignano) & no & GGAG/gtgagta & - & gtgcag/ATGC & KX951751 \\
\hline & tick130 & Italy (Putignano) & no & GGAG/gtgagta & - & gtgcag/ATGC & KX951751 \\
\hline & tick131 & Italy (Putignano) & no & GGAG/gtgagta & - & gtgcag/ATGC & KX951751 \\
\hline & tick137 & Italy (Putignano) & no & GGAG/gtgagta & - & gtgcag/ATGC & KX951751 \\
\hline & tick68 & Greece (Xanthi) & yes & GGAG/gtgagta & 339 & gtgcag/ATGC & KX951747 \\
\hline & tick68 & Greece (Xanthi) & no & GGAG/gtgagta & - & gtgcag/ATGC & KX951751 \\
\hline & tick73 & Greece (Xanthi) & yes & GGAG/gtgagta & 338 & gtgcag/ATGC & KX951739 \\
\hline & tick269 & Greece (Xanthi) & no & GGAG/gtgagta & - & gtgcag/ATGC & KX951751 \\
\hline & tick270 & Greece (Xanthi) & no & GGAG/gtgagta & - & gtgcag/ATGC & KX951751 \\
\hline & tick274 & Greece (Xanthi) & no & GGAG/gtgagta & - & gtgcag/ATGC & KX951751 \\
\hline & tick278 & Greece (Xanthi) & no & GGAG/gtgagta & - & gtgcag/ATGC & KX951751 \\
\hline \multirow[t]{5}{*}{ Temperate lineage } & tick28 & Spain (La Vera, Santa Cruz de Tenerife) & yes & GGAG/gtgagta & 338 & gtgcag/ATGC & KX951740 \\
\hline & tick32 & Spain (La Vera, Santa Cruz de Tenerife) & yes & GGAG/gtgagta & 338 & gtgcag/ATGC & KX951740 \\
\hline & tick216 & Portugal & yes & GGAG/gtgagta & 338 & gtgcag/ATGC & KX951741 \\
\hline & tick210 & Italy (Messina) & no & GGAG/gtgagta & - & gtgcag/ATGC & KX951751 \\
\hline & tick211 & Italy (Messina) & no & GGAG/gtgagta & - & gtgcag/ATGC & KX951751 \\
\hline Rhipicephalus sp. III & tick196 & Pakistan (Punjab) & yes & GGAG/gtgagta & 338 & gcgcag/ATGC & KX951742 \\
\hline \multirow[t]{2}{*}{ Rhipicephalus sp. IV } & tick144 & Nigeria (Plateau State) & yes & GGAG/gtgagta & 336 & gtgcag/ATGC & KX951748 \\
\hline & tick 145 & Nigeria (Plateau State) & yes & GGAG/gtgagta & 336 & gtgcag/ATGC & KX951748 \\
\hline \multirow[t]{5}{*}{ R. turanicus } & tick153 & Italy (Accettura) & yes & GGAG/gtgagta & 335 & gtgcag/ATGC & KX951743 \\
\hline & tick154 & Italy (Accettura) & yes & GGAG/gtgagta & 335 & gtgcag/ATGC & KX951743 \\
\hline & tick155 & Italy (Accettura) & yes & GGAG/gtgagta & 335 & gtgcag/ATGC & KX951744 \\
\hline & tick156 & Italy (Accettura) & yes & GGAG/gtgagta & 335 & gtgcag/ATGC & KX951745 \\
\hline & tick157 & Italy (Accettura) & yes & GGAG/gtgagta & 335 & gtgcag/ATGC & KX951744 \\
\hline \multirow[t]{3}{*}{ R. guilhoni } & tick140 & Nigeria (Plateau State) & yes & GGAG/gtgagta & 335 & gtgcag/ATGC & KX951750 \\
\hline & tick141 & Nigeria (Plateau State) & yes & GGAG/gtgagta & 335 & gtgcag/ATGC & KX951750 \\
\hline & tick142 & Nigeria (Plateau State) & yes & GGAG/gtgagta & 335 & gtgcag/ATGC & KX951750 \\
\hline R. muhsamae & tick148 & Nigeria (Plateau State) & yes & GGAG/gtgagta & 332 & gtgcag/ATGC & KX951749 \\
\hline
\end{tabular}

${ }^{\text {a }}$ Sequence from $\mathrm{Xu}$ et al. [25]

designed within the DNA sequence obtained to increase the specificity of the amplification and used for further analyses of Rhipicephalus ticks. On the basis of the position of the PCR primers designed on the $R$. sanguineus crt sequence available in GenBank, PCR amplicons of about 630 bp were expected [25]. Each PCR amplification was performed in $25 \mu \mathrm{l}$ including $1 \times$ buffer, $200 \mathrm{mM}$ dNTPs, $2.5 \mathrm{mM} \mathrm{MgCl}$, primers at $0.2 \mathrm{mM}, 0.5$ units of high fidelity Taq DNA Polymerase (PhusionH HighFidelity DNA Polymerase, Fermentas-Thermo Scientific Life Science, Milan, Italy), and 20 ng of genomic DNA. Negative controls containing all reagents and water instead 
of DNA, were included in all PCR amplifications to check for contamination. The PCR cycling procedure was: $95{ }^{\circ} \mathrm{C}$ for $5 \mathrm{~min}$ followed by 34 cycles at $93{ }^{\circ} \mathrm{C}$ for $1 \mathrm{~min}, 57^{\circ} \mathrm{C}$ for $1 \mathrm{~min}, 72{ }^{\circ} \mathrm{C}$ for $1 \mathrm{~min} 30 \mathrm{~s}$, and a single final step at $72{ }^{\circ} \mathrm{C}$ for $10 \mathrm{~min}$.

PCR products were run on $1 \%$ agarose, $0.5 \times$ TAE electrophoresis gel, and visualized by staining with Gelred (Sigma-Aldrich, Milan, Italy). The sizes of the DNA fragments were assessed using the $100 \mathrm{bp}$ DNA ladder (Promega, Milan, Italy) run on the same gel. After electrophoresis, PCR products were purified using the NucleoSpin Gel and PCR Cleanup kit (MachereyNagel, Carlo Erba, Milan, Italy) following the manufacturer's protocol. Two PCR bands of about 630 and $300 \mathrm{bp}$, respectively, were observed by running the PCR amplicons of the Rhipicephalus sp. I tick68 individual (see Results section). Both bands were then excised by gel and purified as described above.

PCR products were sequenced using ABI PRISM 3700 DNA sequencer by Macrogen Inc. (www.macrogen.com). All individuals were double sequenced using both forward and reverse primers to check for consistency and all crt sequences that were found unique were re-amplified and re-sequenced. Sequences were edited and aligned using the software Chromas 2.31 (Technelysium Pty Ltd, Australia) and Clustal X 2.1 [41], respectively. Polymorphisms of nucleotide and amino-acidic sequences were assessed using the software DnaSP 5.10.1 [42]. Pairwise p-distances between the crt sequences obtained were computed using MEGA 7.0 [43]. The genealogical relationships between crt sequences were investigated by constructing a phylogenetic network using the medianjoining (MJ) network algorithm as implemented in the NETWORK 5.0.0 software (Fluxus Technology Ltd). The loops in the resulting phylogenetic network were resolved by applying the criteria described by Pfenninger and Posada [44]. The R. sanguineus (s.l.) crt gene sequence AY395275 [25] was included in the analyses for comparison.

\section{Results}

Successful PCR amplifications were obtained from 35 individuals. Among them, 24 showed PCR amplicons of the expected size, while ten individuals showed amplicons of about $300 \mathrm{bp}$ (two belonging to the temperate lineage and eight Rhipicephalus sp. I) and one individual (Rhipicephalus. sp. I tick68) showed PCR amplicons of both sizes (Table 1, Fig. 1).

All PCR amplicons were sequenced and the sequences obtained were deposited in GenBank (accession numbers KX951737-KX951751) (Table 1). By comparing the obtained sequences with the genomic crt sequence of R. sanguineus (s.l.) from Colombia available in GenBank (AY395275), we found nucleotide identity ranging from
95\% (R. muhsamae tick148) to 99\% (R. sanguineus (s.l.) tick224), showing that all sequences obtained corresponded to the target crt gene region. No double peaks were found in the sequence chromatograms, showing that no heterozygous individuals were found.

The longer crt fragments had the expected exon-intron structure, including two fragments of exon regions and one intron region of 332-340 bp (Table 1, Fig. 2, Additional file 1: Figure S1). Crt exon-intron structure was found in all individuals belonging to the tropical lineage, Rhipicephalus sp. III, Rhipicephalus sp. IV, $R$. turanicus, $R$. guilhoni and $R$. muhsamae analysed, as well as in three out of the five temperate lineage individuals and in two out of the 11 Rhipicephalus sp. I individuals analysed (Table 1). Fourteen unique sequences were identified by 49 polymorphic sites ( 11 sites in the exon regions with eight synonymous and three non-synonymous changes) (Additional file 1: Figure S1).

The mean pairwise $p$-distance between all crt-intron sequences was $2 \%$ (standard error, $\mathrm{SE}=0.3 \%$; range $=$ $0.2-4.3 \%)$. Mean pairwise $c r t$ divergence within taxa was $0.3 \%(\mathrm{SE}=0.2 \%)$ for tropical lineage, $1.4 \%(\mathrm{SE}=0.5 \%)$ for Rhipicephalus sp. I, 0.5\% (SE =0.3\%) for Rhipicephalus sp. II, and $0.2 \%(\mathrm{SE}=0.2 \%)$ for $R$. turanicus individuals. Mean pairwise divergence between taxa ranged from $0.3 \%$ $(\mathrm{SE}=0.2 \%)$ (between tropical and temperate lineages) and $4.1 \%(\mathrm{SE}=0.8 \%)$ (between Rhipicephalus sp. III and R. muhsamae) (Table 2).

The genealogical relationships between the crt-intron alleles are shown in the median-joining network reported in Fig. 2. Distinct lineages were observed for $R$. turanicus, R. guilhoni, R. muhsamae, Rhipicephalus sp. III and Rhipicephalus sp. IV. Individuals belonging to the tropical and temperate lineages were more closely related to each other, but showed distinct alleles. The Rhipicephalus sp. I tick73 allele derived from the Rhipicephalus sp. II tick28 allele, while the Rhipicephalus sp. I tick68 allele derived from a missing intermediate allele.

Contrary to the crt-intron fragments, the smaller crt fragments did not show the expected intron region. These crt intron-absent alleles were all identical (Fig. 2; Additional file 1: Figure S1) across ten individuals among those analysed: all Rhipicephalus sp. I ticks with the exception of the Rhipicephalus sp. I tick73, that showed a crt intron-present allele, and the Rhipicephalus sp. I tick68, that showed both intron-present and intronabsent alleles (Table 1, Figs. 1 and 2); two temperate lineage individuals (Rhipicephalus sp. II tick210, Rhipicephalus sp. II tick211) (Table 1).

\section{Discussion}

Sequence structure and diversity of the crt gene have been poorly investigated in Rhipicephalus spp. ticks $[24,25]$. In this paper, our first aim was to assess if the 


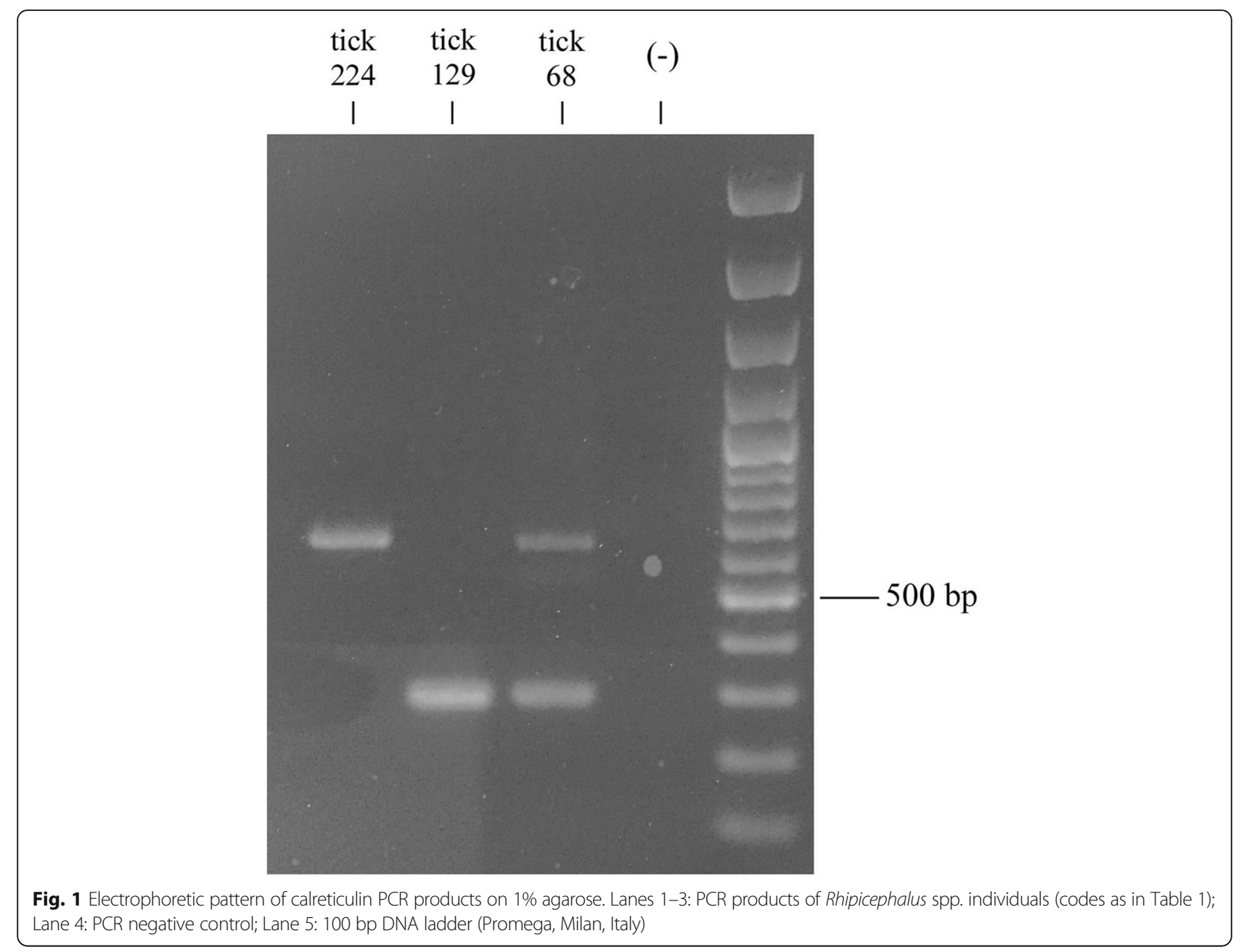

crt gene structure is conserved among $R$. sanguineus group taxa and other species, such as $R$. muhsamae. Previous analyses of the crt gene structure in 28 hard tick species (one individual per species) belonging to seven genera (Amblyomma, Boophilus, Dermacentor, Hyalomma, Haemaphysalis, Ixodes and Rhipicephalus) showed that crt gene has only one intron and that its position is conserved [24, 25]. By sequencing the crt exon-intron region from eight species/OTUs of Rhipicephalus, we showed the occurrence of crt intronpresent alleles in all tropical lineage, $R$. turanicus, $R$. guilhoni, Rhipicephalus sp. III, Rhipicephalus sp. IV and $R$. muhsamae individuals, from different geographic regions (Table 1), supporting the occurrence of an intron in the crt gene at the expected position [24, 25]. Surprisingly, by analysing ticks belonging to Rhipicephalus sp. I and temperate lineage, we found both crt intron-present and intron-absent alleles (Table 1). Therefore, our results, first, supported the conserved position of the intron region in the crt gene as shown by $\mathrm{Xu}$ et al. [25]; second, they highlighted a previously overlooked variation in the crt exon-intron structure among Rhipicephalus spp., and among hard ticks in general.

Introns are a common feature of the eukaryote genomes $[45,46]$. The intron density can vary by more than three orders of magnitude among genomes of different organisms. Different numbers of introns in homologous genes have been documented for several closely or distantly related taxa [47]. On the contrary, only few cases of intra-specific variation (i.e. intron presence-absence polymorphism within or among populations of the same species) have been documented to date [48-50]. In arthropods, it has been found in Drosophila melanogaster populations at the locus $4 f-r n p$ [48] and in Drosophila teissieri, where the intron presence-absence polymorphism observed at the jingwei gene was ascribed to the action of positive selection [49]. The crt gene in $R$. sanguineus group adds to these rare cases. Indeed, both crt intron-present and intron-absent alleles were found in Rhipicephalus sp. I and temperate lineage ticks, and even both alleles were found within the same population of Rhipicephalus sp. I (i.e. Xanthi, Greece and Putignano, Italy) (Table 1). 


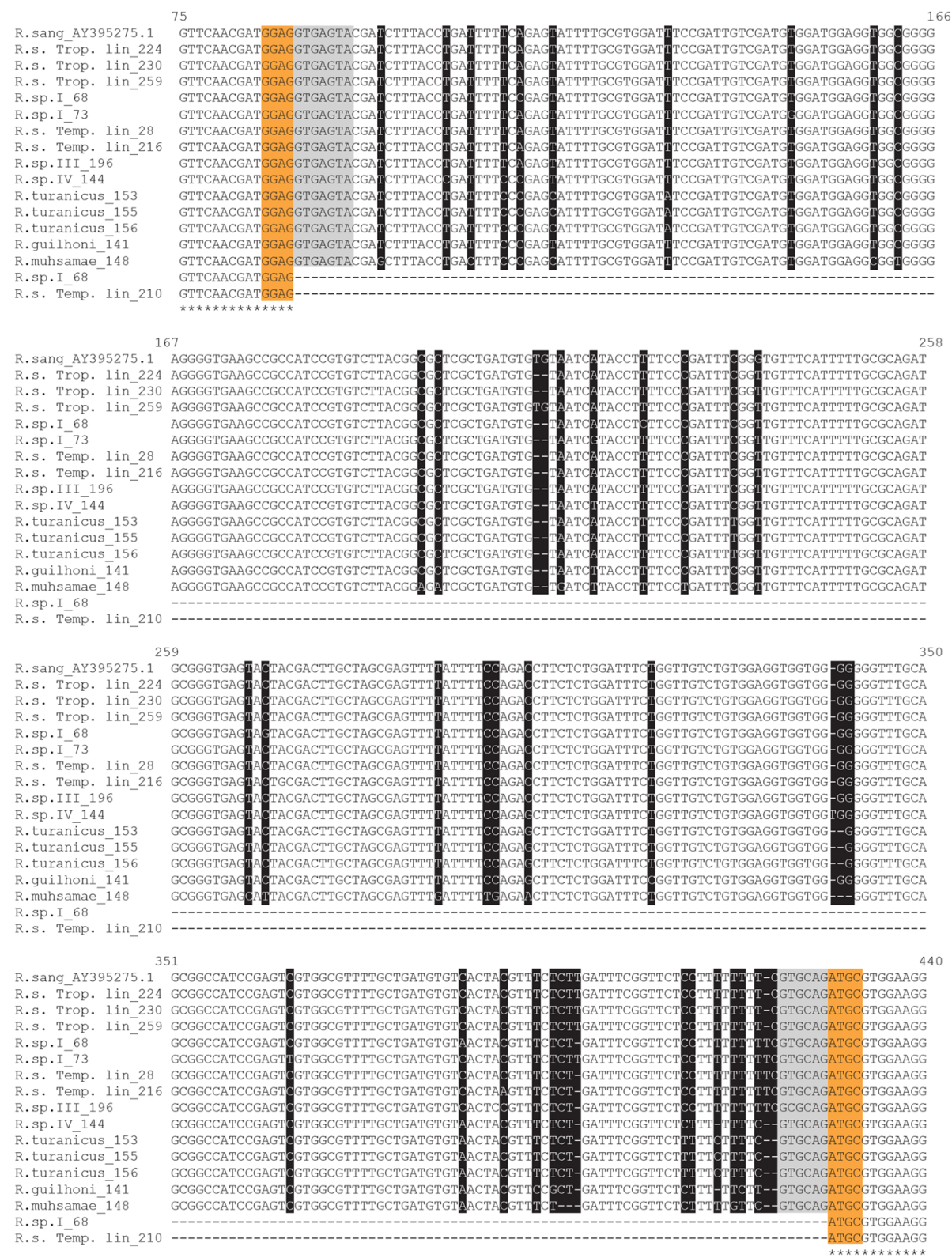

Fig. 2 Alignment of crt exon-intron region in Rhipicephalus spp. individuals analysed (codes as in Table 1). Nucleotides in orange boxes belong to exon regions in 5' and 3' splice donor regions. Nucleotides in light grey boxes belong to intron region in $5^{\prime}$ and $3^{\prime}$ splice donor regions. Nucleotides in black boxes indicate sequence identity in intron region. Asterisks show nucleotide identity in exon regions. Numbers indicate the nucleotide position of the R. sanguineus (s.l.) crt sequence AY395275.1 [25]. Abbreviations: R.s. Trop. lin., Rhipicephalus sanguineus (s.l.) "Tropical lineage"; R.s. Temp. lin., Rhipicephalus sanguineus (s.l.) "Temperate lineage"

The crt gene in Rhipicephalus spp. is therefore a candidate study-system to investigate the early stages of intron gain/ loss before fixation at the species level, as well as to investigate the evolutionary and ecological factors underlying their persistence and diffusion. In this context, because introns can significantly affect gene expression $[45,51]$, future studies are warranted to investigate the phenotypic effects of the intron presence/absence polymorphism observed (i.e. crt gene expression and, ultimately, the tick blood meal success) in order to assess its potential adaptive value.

In addition, the potential utility of the crt gene as molecular marker has been herein assessed. Taxonomic status and phylogenetic relationships between the members of the $R$. sanguineus group are still debated [37]. Mitochondrial DNA (mtDNA) regions such as $16 \mathrm{~S}$ and $12 \mathrm{~S}$ ribosomal DNA (rDNA) and cytochrome $c$ oxidase subunit 1 ( $\operatorname{cox} 1)$ gene, have been widely used as genetic 
Table 2 Mean pairwise genetic distance between the Rhipicephalus spp. analysed for the calreticulin gene sequences. Ticks are encoded as in Table 1. Mean p-distances (below the diagonal) have been estimated as implemented in the MEGA 7.0 software. Only sequences with intron region were used. Standard error estimates are shown above the diagonal and were obtained by a bootstrap procedure (1,000 replicates)

\begin{tabular}{lllllllll}
\hline & Tropical lineage & R. sp. I & Temperate lineage & R. sp. III & R. sp. IV & R. turanicus & R. guilhoni & R. muhsamae \\
\hline Tropical lineage & - & 0.003 & 0.002 & 0.003 & 0.005 & 0.006 & 0.007 & 0.007 \\
Rhipicephalus sp. I & 0.009 & - & 0.003 & 0.004 & 0.005 & 0.006 & 0.007 & 0.007 \\
Temperate lineage & 0.003 & 0.009 & - & 0.004 & 0.005 & 0.006 & 0.007 & 0.007 \\
Rhipicephalus sp. III & 0.008 & 0.014 & 0.009 & - & 0.006 & 0.007 & 0.007 & 0.008 \\
Rhipicephalus sp. IV & 0.018 & 0.018 & 0.018 & 0.022 & - & 0.005 & 0.005 & 0.007 \\
R. turanicus & 0.025 & 0.027 & 0.026 & 0.027 & 0.015 & - & 0.006 & 0.007 \\
R. guilhoni & 0.027 & 0.028 & 0.028 & 0.029 & 0.017 & 0.023 & - & 0.008 \\
R. muhsamae & 0.039 & 0.039 & 0.040 & 0.041 & 0.034 & 0.039 & 0.039 & - \\
\hline
\end{tabular}

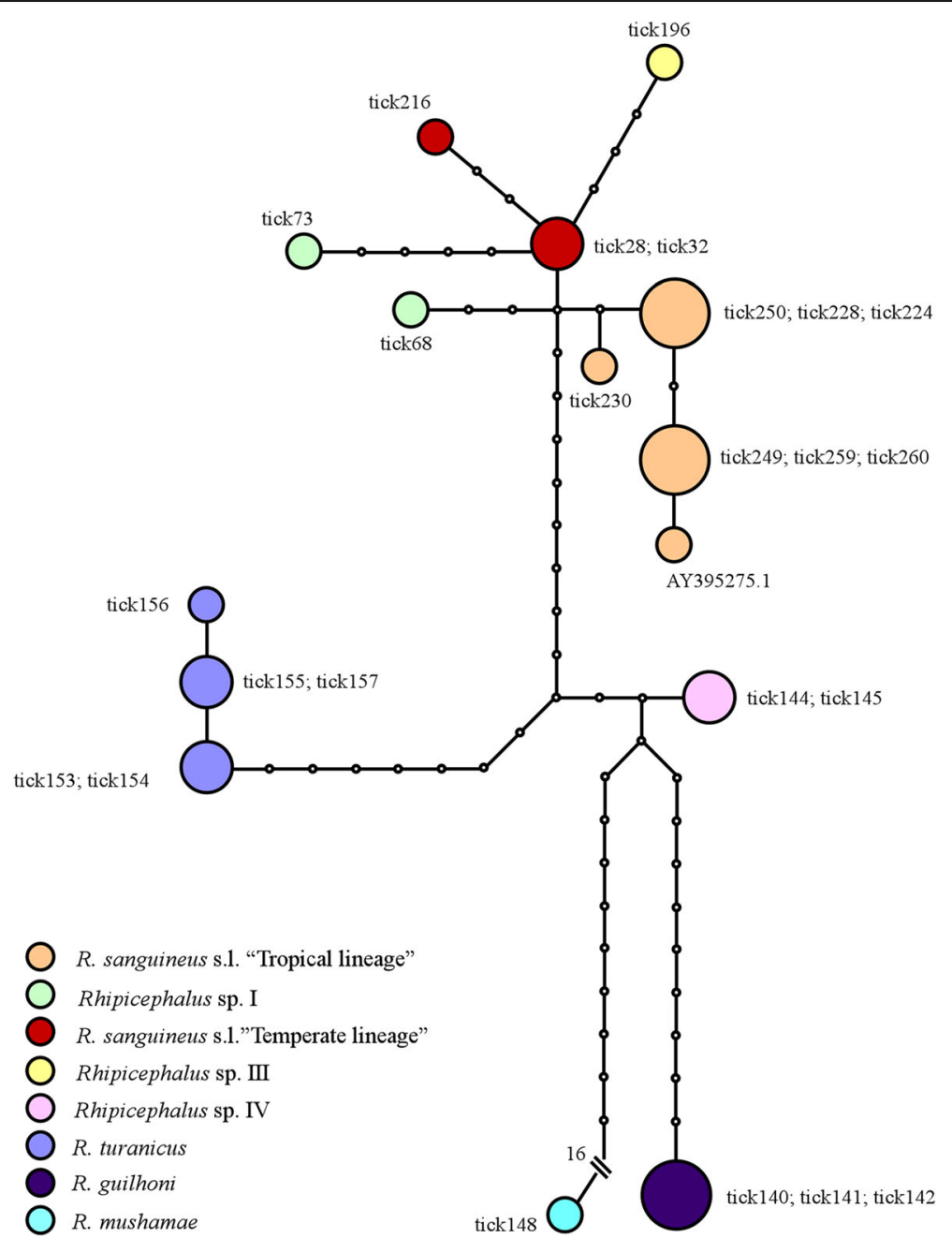

Fig. 3 Median-joining network showing phylogenetic relationships among the crt-intron sequences of the Rhipicephalus spp. ticks analysed. Crt alleles are shown as circles with sizes corresponding to their frequencies in the total sample and colour corresponding to Rhipicephalus taxon where they have been observed. Alleles are coded as in Table 1. Dots indicate missing intermediate alleles 
markers that have proven to be useful in identifying cryptic diversity within the $R$. sanguineus group [36, 38-40, 52, 53]. However, because the mtDNA genome is inherited as a unit, mitochondrial genes cannot be regarded as independent sources of phylogenetic information. Furthermore, single loci are subject to issues of non-concordance between gene and species trees due to introgression, incomplete lineage sorting, natural selection and arbitrary divergence that could obscure the real population structure [54-57]. Multilocus analysis, using both mtDNA and nuclear DNA markers, could overcome the above drawbacks. Among nuclear markers, the internal transcribed spacer-2 (ITS-2) has been used in some studies, but little interspecific divergence was found and this marker was unable to distinguish between Rhipicephalus spp., such as between the tropical lineage and $R$. turanicus $[58,59]$ or between the tropical lineage, $R$. guilhoni and R. turanicus [36]. The polymorphism observed at the crt gene fragment analysed, concordantly with mtDNA markers [40], showed that $R$. muhsamae is the most distantly related taxon among those analysed (Fig. 3, Table 2). The above findings support the suitability of the crt gene for rapid molecular recognition of $R$. sanguineus group taxa that ITS-2 region failed to identify, as well as its potential utility for phylogenetic studies in association with other markers.

From a taxonomic point of view, of particular interest are the findings that Rhipicephalus sp. I and the temperate lineage have both crt intron-present and intron-absent alleles (Table 1). These two taxa have been recently described and characterized by morphological and molecular analyses (variation at the mtDNA loci $12 \mathrm{~S}$ rDNA, 16S rDNA and cox1) [40]. Under the Rhipicephalus sp. I were included ticks from southern Italy and Greece, while the so-called temperate lineage comprised ticks from temperate regions of the Americas and Europe [40]. The observed sharing of crt intron-present and intron-absent alleles between Rhipicephalus sp. I and the temperate lineage could be due to current gene exchange. Interestingly, the Rhipicephalus sp. I tick68 showed both alleles, which could support that this taxon has a heterozygous genotype at this locus. Alternatively, reproductive isolation could be actually completed and the observed pattern could be the signature of past hybridization events or incomplete lineage sorting [54-56]. Crossbreeding experiments as well as the analysis of Rhipicephalus sp. I and temperate lineage populations may help to test these hypotheses.

\section{Conclusions}

The tick saliva, as in other haematophagous arthropods, is involved in the success of blood feeding, in pathogen transmission and host allergic responses. The characterization of the genes encoding for the salivary molecular components, such as CRTs, is pivotal to understand the mechanisms of tick-host interaction during the blood meal as well as to develop tick control strategies based on their inhibition [7, 9, 13, 16, 17]. In this study we focused on the $R$. sanguineus group and expanded previous studies about the characterization of crt gene in hard ticks. The unexpected finding of intron presence-absence polymorphism in the $c r t$ gene within and among Rhipicephalus spp. opens some questions about how widespread is this polymorphism among hard ticks and its evolutionary significance. What are the phenotypic effects of the intron presence/absence in $c r t$ gene and how intron absence can affect tick fitness and tick-host interactions? What are the evolutionary processes that underlie and maintain the sharing of intron-present and intron-absent alleles in Rhipicephalus sp. I and in the temperate lineage? The answers to these questions will contribute not only to our understanding about the biology and ecology of the $R$. sanguineus group ticks, but also may help address some unresolved questions about the evolution of eukaryotic genes.

\section{Additional file}

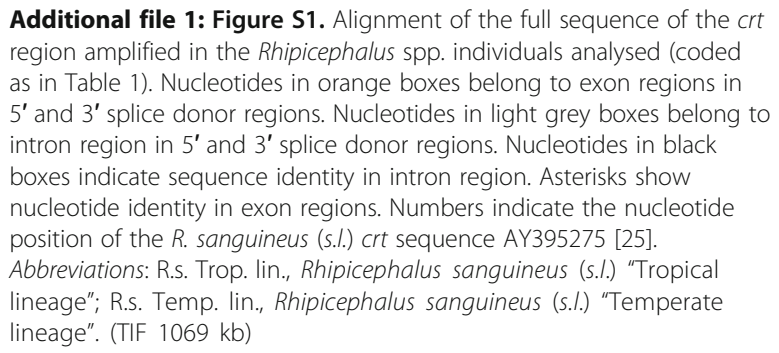

Additional file 1: Figure S1. Alignment of the full sequence of the crt region amplified in the Rhipicephalus spp. individuals analysed (coded as in Table 1). Nucleotides in orange boxes belong to exon regions in $5^{\prime}$ and $3^{\prime}$ splice donor regions. Nucleotides in light grey boxes belong to intron region in $5^{\prime}$ and $3^{\prime}$ splice donor regions. Nucleotides in black boxes indicate sequence identity in intron region. Asterisks show nucleotide identity in exon regions. Numbers indicate the nucleotide position of the R. sanguineus (s.l.) crt sequence AY395275 [25]. Abbreviations: R.s. Trop. lin., Rhipicephalus sanguineus (s.l.) "Tropical lineage"; R.s. Temp. lin., Rhipicephalus sanguineus (s.l.) "Temperate lineage". (TIF $1069 \mathrm{~kb}$ )

\section{Acknowledgements}

We would like to thank Alessandra Spanò for technical help.

Funding

This study was supported by the MIUR (Italian Minister of University and Research), grant number C26A149B88.

Availability of data and materials

Nucleotide sequences obtained in the present study have been deposited in the GenBank database with the following accession numbers: KX951737-KX951751.

\section{Authors' contributions}

DP, FDT, DO and SU conceived the study; MSL, VM, RI participated in the development of the protocol; VM, MSL performed the experiments; DP, VM analysed the data; DP, VM, SU wrote the manuscript. All authors read and approved the final manuscript.

Competing interests

The authors declare that they have no competing interests.

Ethics approval and consent to participate

Not applicable. 


\section{Author details}

Department of Environmental Biology, Sapienza University of Rome, Rome, Italy. ${ }^{2}$ Department of Veterinary Medicine, University of Bari, 70010 Valenzano, Bari, Italy. ${ }^{3}$ Department of Immunology, Aggeu Magalhães Research Centre, Oswaldo Cruz Foundation, 50740465 Recife, PE, Brazil.

Received: 22 September 2016 Accepted: 23 November 2016 Published online: 12 December 2016

\section{References}

1. Ostwald TJ, MacLennan DH. Isolation of a high affinity calcium-binding protein from sarcoplasmic reticulum. J Biol Chem. 1974;249:974-9.

2. Johnson S, Michalak M, Opas M, Eggleton P. The ins and outs of calreticulin: from the ER lumen to the extracellular space. Trends Cell Biol. 2001;11:122-9.

3. Ghiran I, Klickstein LB, Nicholson-Weller A. Calreticulin is at the surface of circulating neutrophils and uses CD59 as an adaptor molecule. J Biol Chem. 2003;278:21024-31.

4. Michalak M, Corbett EF, Mesaeli N, Nakamura K, Opas M. Calreticulin: one protein, one gene, many functions. Biochem J. 1999:344:281-92.

5. Michalak M, Groenendyk J, Szabo E, Gold LI, Opas M. Calreticulin, a multiprocess calcium-buffering chaperone of the endoplasmic reticulum. Biochem J. 2009:417:651-66.

6. Qiu Y, Michalak M. Transcriptional control of the calreticulin gene in health and disease. Int J Biochem Cell Biol. 2009;41:531-8.

7. Ribeiro JM, Francischetti IM. Role of arthropod saliva in blood feeding: sialome and post-sialome perspectives. Annu Rev Entomol. 2003:48:73-8.

8. Ribeiro JM, Anderson JM, Manoukis NC, Meng Z, Francishetti IM. A further insight into the sialome of the tropical bont tick, Amblyomma variegatum. BMC Genom. 2011;12:136.

9. Kazimírová M, Štibrániová I. Tick salivary compounds: their role in modulation of host defences and pathogen transmission. Front Cell Infect Microbiol. 2013;3:43

10. Garcia GR, Gardinassi LG, Ribeiro JM, Anatrielo E, Ferreira BR, Moreira HN, et al. The sialotranscriptome of Amblyomma triste, Amblyomma parvum and Amblyomma cajennense ticks, uncovered by 454-based RNA-seq. Parasit Vectors. 2014;7:430.

11. Bazzocchi C, Mariconti M, Sassera D, Rinaldi L, Martin E, Cringoli G, et al. Molecular and serological evidence for the circulation of the tick symbiont Midichloria (Rickettsiales: Midichloriaceae) in different mammalian species. Parasit Vectors. 2013;6:350

12. Tirloni L, Reck J, Terra RM, Martins JR, Mulenga A, Sherman NE, et al. Proteomic analysis of cattle tick Rhipicephalus (Boophilus) microplus saliva: a comparison between partially and fully engorged females. PLoS One. 2014;9:E94831.

13. Kotsyfakis M, Schwarz A, Erhart J, Ribeiro JM. Tissue- and time-dependent transcription in Ixodes ricinus salivary glands and midguts when blood feeding on the vertebrate host. Sci Rep. 2015;5:9103.

14. Xu XL, Cheng TY, Yang H, Yan F, Yang Y. De novo sequencing, assembly and analysis of salivary gland transcriptome of Haemaphysalis flava and identification of sialoprotein genes. Infect Genet Evol. 2015;32:135-42.

15. Chmelař J, Kotál J, Kopecký J, Pedra JHF, Kotsyfakis M. All for one and one for all on the tick-host battlefield. Trends Parasitol. 2016;32:368-77.

16. Jaworski DC, Simmen FA, Lamoreaux W, Coons LB, Muller MT, Needham GR. A secreted calreticulin protein in ixodid tick (Amblyomma americanum) saliva. J Insect Physiol. 1995;41:369-75.

17. Bowman AS, Gengler CL, Surdick MR, Zhu K, Essenberg RC, Sauer JR, et al. A novel phospholipase $A_{2}$ activity in saliva of the lone star tick, Amblyomma americanum (L.). Exp Parasitol. 1997;87:121-32. 10.

18. Sanders ML, Jaworski DC, Sanchez JL, DeFraites RF, Glass GE, Scott AL, et al. Antibody to a cDNA-derived calreticulin protein from Amblyomma americanum as a biomarker of tick exposure in humans. Am J Trop Med Hyg. 1998:59:279-85.

19. Sanders ML, Glass GE, Nadelman RB, Wormser GP, Scott AL, Raha S, et al. Antibody levels to recombinant tick calreticulin increase in humans after exposure to Ixodes scapularis (Say) and are correlated with tick engorgement indices. Am J Epidemiol. 1999;149:777-84.

20. Alarcon-Chaidez F, Ryan R, Wikel S, Dardick K, Lawler C, Foppa IM, et al. Confirmation of tick bite by detection of antibody to Ixodes calreticulin salivary protein. Clin Vaccine Immunol. 2006:13:1217-22.

21. Parizi LF, Rech H, Ferreira CA, Imamura S, Ohashi K, Onuma M, et al. Comparative immunogenicity of Haemaphysalis longicornis and Rhipicephalus (Boophilus) microplus calreticulins. Vet Parasitol. 2009;164:282-90.
22. Domingos A, Antunes S, Borges L, do Rosário VE. Approaches towards tick and tick-borne diseases control. Rev Soc Bras Med Trop. 2013;46:265-9.

23. Sanchez-Ferreira CA, Da Silva Vaz Jr I, da Silva SS, Haag KL, Valenzuela JG, Masuda A. Cloning and partial characterization of Boophilus microplus (Acari: Ixodidae) calreticulin. Exp Parasitol. 2002;101:25-34.

24. Xu G, Fang QQ, Keirans JE, Durden LA. Cloning and sequencing of putative calreticulin complementary DNA from four hard tick species. J Parasitol. 2004;90:73-8.

25. Xu G, Fang QQ, Sun Y, Keirans JE, Durden LA. Hard tick calreticulin (CRT) gene coding regions have only one intron with conserved positions and variable sizes. J Parasitol. 2005;91:1326-31.

26. Gao J, Luo J, Fan R, Fingerle V, Guan G, Liu Z, et al. Cloning of a cDNA clone encoding calreticulin from Haemaphysalis qinghaiensis (Acari: Ixodidae). Parasitol Res. 2008;102:737-46.

27. Antunes S, Galindo RC, Almazan C, Rudenko N, Golovchenko M, Grubhoffer $L$, et al. Functional genomics studies of Rhipicephalus (Boophilus) annulatus ticks in response to infection with the cattle protozoan parasite, Babesia bigemina. Int J Parasitol. 2012;42:187-95.

28. Galay RL, Umemiya-Shirafuji R, Mochizuki M, Fujisaki K, Tanaka T. RNA interference - a powerful functional analysis tool for studying tick biology and its control. Abdurakhmonov, IY, editor, RNA Interference. In Tech; 2016. doi:10.5772/61577.

29. Palumbi SR, Baker CS. Contrasting population structure from nuclear intron sequences and mtDNA of humpback whales. Mol Biol Evol. 1994;11:426-35.

30. Creer S. Choosing and using introns in molecular phylogenetics. Evol Bioinform. 2007:3:99-108.

31. Porretta D, Mastrantonio V, Mona S, Epis S, Montagna M, Sassera D, et al. The integration of multiple independent data reveals an unusual response to Pleistocene climatic changes in the hard tick Ixodes ricinus. Mol Ecol. 2013:22:1666-82

32. White VL, Endersby NC, Chan J, Hoffmann AA, Weeks AR. Developing exonprimed intron-crossing (EPIC) markers for population genetic studies in three Aedes disease vectors. Insect Sci. 2015;22:409-23.

33. Dantas-Torres F. The brown dog tick, Rhipicephalus sanquineus (Latreille, 1806) (Acari: Ixodidae): from taxonomy to control. Vet Parasitol. 2008;152:173-85.

34. Dantas-Torres F, Chomel BB, Otranto D. Ticks and tick-borne diseases: a one health perspective. Trends Parasitol. 2012;28:437-46.

35. Gray J, Dantas-Torres F, Estrada-Peña A, Levin M. Systematics and ecology of the brown dog tick, Rhipicephalus sanguineus. Ticks Tick Borne Dis. 2013;4:171-80.

36. Latrofa MS, Dantas-Torres F, Annoscia G, Cantacessi C, Otranto D. Comparative analyses of mitochondrial and nuclear genetic markers for the molecular identification of Rhipicephalus spp. Infect Genet Evol. 2013;20:422-7.

37. Dantas-Torres F, Otranto D. Further thoughts on the taxonomy and vector role of Rhipicephalus sanquineus group ticks. Vet Parasitol. 2015:208:9-13.

38. Hekimoğlu O, Sağlam IK, Özer N, Estrada-Peña A. New molecular data shed light on the global phylogeny and species limits of the Rhipicephalus sanquineus complex. Ticks Tick Borne Dis. 2016;7:798-807.

39. Sanches GS, Évora PM, Mangold AJ, Jittapalapong S, Rodriguez-Mallon A, Guzmán PEE, et al. Molecular, biological, and morphometric comparisons betweendifferent geographical populations of Rhipicephalus sanguineus sensu lato (Acari: Ixodidae). Vet Parasitol. 2016;215:78-87.

40. Dantas-Torres F, Latrofa MS, Annoscia G, Giannelli A, Parisi A, Otranto D. Morphological and genetic diversity of Rhipicephalus sanguineus s.l. from the New and Old worlds. Parasit Vectors. 2013;6:213.

41. Larkin MA, Blackshields G, Brown NP, Chenna R, McGettigan PA, McWilliam $H$, et al. Clustal W and Clustal X version 2.0. Bioinformatics. 2007;23:2947-8.

42. Librado P, Rozas J. DnaSP v5: a software for comprehensive analysis of DNA polymorphism data. Bioinformatics. 2009;25:1451-2.

43. Kumar S, Stecher G, Tamura K. MEGA7: molecular evolutionary genetics analysis version 7.0 for bigger datasets. Mol Biol Evol. 2016;33:1870-4. msw054.

44. Pfenninger M, Posada D. Phylogeographic history of the land snail Candidula unifasciata (Poiret 1801) (Helicellinae, Stylommatophora): fragmentation, corridor migration and secondary contact. Evolution. 2002:56:1776-88.

45. Rogozin I, Carmel L, Csuros M, Koonin E. Origin and evolution of sliceosomal introns. Biol Direct. 2012;7:11.

46. Heyn P, Kalinka AT, Pavel Tomancak P, Karla M, Neugebauer KM. Introns and gene expression: cellular constraints, transcriptional regulation, and evolutionary consequences. Bioessays. 2014;37:148-54.

47. Jeffares DC, Mourier T, Penny D. The biology of intron gain and loss. Trends Genet. 2006;22:16-22. 
48. Feiber AL, Rangarajan J, Vaughn JC. The evolution of single-copy Drosophila nuclear 4f-rnp genes: spliceosomal intron losses create polymorphic alleles. J Mol Evol. 2002;55:401-13.

49. Llopart A, Comeron JM, Brunet FG, Lachaise D, Long M. Intron presenceabsence polymorphism in Drosophila driven by positive Darwinian selection. PNAS. 2002;99:8121-6.

50. Torriano SFF, Stukenbrock EH, Brunner PC, McdONALD BA, Croll D. Evidence for extensive recent intron transposition in closely related fungi. Curr Biol. 2011;21:2017-22.

51. Chorev M, Carmel L. The function of introns. Front Genet. 2012;3:1-14.

52. Burlini L, Teixeira KR, Szabó MP, Famadas KM. Molecular dissimilarities of Rhipicephalus sanguineus (Acari: Ixodidae) in Brazil and its relation with samples throughout the world: is there a geographical pattern? Exp Appl Acarol. 2010;50:361-74.

53. Moraes-Filho J, Marcili A, Nieri-Bastos FA, Richtzenhain LJ, Labruna MB. Genetic analysis of ticks belonging to the Rhipicephalus sanguineus group in Latin America. Acta Trop. 2011:1:51-5.

54. Galtier N, Nabholz B, Glémin S, Hurst GD. Mitochondrial DNA as a marker of molecular diversity: a reappraisal. Mol Ecol. 2009;18:4541-50.

55. Toews DPL, Brelsford A. The biogeography of mitochondrial and nuclear discordance in animals. Mol Ecol. 2012;21:3907-30.

56. Patwardhan A, Samit Ray S, Amit Roy A. Molecular Markers in Phylogenetic Studies-A Review. J Phylogen Evolution Biol. 2014;2:2.

57. Mastrantonio V, Porretta D, Urbanelli S, Crasta G, Nascetti G. Dynamics of mtDNA introgression during species range expansion: insights from an experimental longitudinal study. Sci Rep. 2016;6:30355.

58. Zahler M, Filippova NA, Morel PC, Gothe R, Rinder H. Relationships between species of the Rhipicephalus sanguineus group: a molecular approach. J Parasitol. 1997;83:302-6.

59. Beati L, Keirans JE. Analysis of the systematic relationships among ticks of the genera Rhipicephalus and Boophilus (Acari: Ixodidae) based on mitochondrial 125 ribosomal DNA gene sequences and morphological characters. J Parasitol. 2001:87:32-48.

\section{Submit your next manuscript to BioMed Central and we will help you at every step:}

- We accept pre-submission inquiries

- Our selector tool helps you to find the most relevant journal

- We provide round the clock customer support

- Convenient online submission

- Thorough peer review

- Inclusion in PubMed and all major indexing services

- Maximum visibility for your research

Submit your manuscript at www.biomedcentral.com/submit 